\title{
Etnobotânica de Parahancornia fasciculata (Apocynaceae): extração, usos e comercialização do leite de amapá na comunidade da ilha Trambioca, Barcarena, Pará, Brasil
}

Ethnobotany of Parahancornia fasciculata (Apocynaceae): extraction, uses and commercialization of amapá milk in the community of Trambioca island, Barcarena, Pará,

Brazil

\author{
R. L. de Sousa*1; J. F. S. Costa ${ }^{1}$; J. M. Costa ${ }^{2}$; M. G. S. Pereira ${ }^{1}$; Y. E. M. \\ Cordeiro $^{1}$ \\ ${ }^{1}$ Universidade Federal do Pará “Campus Universitário de Abaetetuba” (UFPA), 684400-000, Abaetetuba, Pará, \\ Brasil. \\ ${ }^{2}$ Instituto Federal do Pará “Campus de Abaetetuba” (IFPA), 684400-000, Abaetetuba, Pará, Brasil.
}

*e-mail: ronaldosousa@ufpa.br

(Recebido em 12 de janeiro de 2019; aceito em 18 de novembro de 2019)

\begin{abstract}
A espécie Parahancornia fasciculata produz um exsudato medicinal na forma de látex, denominado leite de amapá amargoso, bastante utilizado na Amazônia brasileira por suas propriedades medicinais. $\mathrm{O}$ presente trabalho teve como objetivo estudar as formas de extração, os usos e a comercialização do leite de amapá na comunidade da ilha Trambioca, Barcarena-PA. Os colaboradores foram selecionados por uma abordagem não probabilística "bola de neve". A extração do leite de amapá pelos moradores da ilha Trambioca é exercida por homens com idade entre 39 a 76 anos e a cadeia de extração, consumo e comercialização do leite de amapá na ilha envolve o extrator, o atravessador e os consumidores local e externo. Os consumidores do exsudato obtido do amapazeiro abrangeram todas as faixas etárias entrevistadas, mais da metade (64\%) tinham renda de até dois salários mínimos e tomaram o leite de amapá devido a facilidade de conseguir o produto e por ser natural. O látex de amapá possui propriedades farmacológicas para o tratamento de doenças que afetam o sistema respiratório e fraqueza física.

Palavras-chave: Látex medicinal, exsudato do amapazeiro, medicina popular.
\end{abstract}

The species Parahancornia fasciculata produces a medicinal exudate in the form of latex, called the bitter amapá milk, widely used in the Brazilian Amazon for its medicinal properties. The present work had as objective to study the forms of extraction, the uses and the commercialization of the amapá milk in the community of the island, Barcarena-PA. The employees were selected by a non-probabilistic "snowball" approach. The extraction of the amapá milk by the inhabitants of the island of Trambioca is carried out by men aged between 39 and 76 years and the chain of extraction, consumption and commercialization of the milk of amapá in the island Trambioca involves the extractor, the intermediary and the local and external consumers. Consumers of the exudate obtained from the amapazeiro covered all the age groups interviewed, more than half $(64 \%)$ had income of up to two minimum wages and took the milk of amapá due to the easy of obtaining the product and for being natural. The latex of amapá has pharmacological properties for the treatment of diseases that affect the respiratory system and physical weakness.

Keywords: Medicinal latex, exudate of the amapazeiro, folk medicine.

\section{INTRODUÇÃO}

Na região norte do Brasil, as árvores conhecidas como amapazeiros são produtoras de látex, pertencentes principalmente às famílias Apocynaceae e Moraceae [1]. A espécie Parahancornia fasciculata (Poir) Benoist (Apocynaceae) é uma planta frutífera de tronco ereto e elevado, sendo a copa constituída por muitos galhos opostos e independentes entre si [2, 3]. As folhas são lanceoladas, opostas, com 12 a 15 nervuras secundárias maiores [4]. Os frutos são globosos, semelhantes à baga, com cerca de $8 \mathrm{~cm}$ de diâmetro, pericarpo roxo-escuro quando maduro, espesso-carnoso com um a $1,5 \mathrm{~cm}$ de espessura envolvendo a polpa doce [5]. A semente apresenta coloração marrom-escura e amarelo-claro, podendo conter borda marrom com o centro amarelo. Morfologicamente, lisa, ovoide-achatada, hilo do tipo central e ovalado [6]. 
A $P$. fasciculata ocorre na região Norte e produz um exsudato medicinal na forma de látex, denominado leite de amapá amargoso, bastante utilizado na Amazônia brasileira por suas propriedades medicinais, no tratamento de doenças do sistema respiratório, gastrite, fraqueza, cicatrização [3], no combate a verminoses e anemia [2]. Esse espectro de atividades biológicas pode ser explicado em função de sua composição química. No extrato diclorometânico da casca e do látex foram isolados e identificados os triterpenos pentacíclicos lupeol, $\beta$-amirina e $\alpha$-amirina e seus derivados acetilados $[7,8]$. Utilizando a mesma metodologia, das raízes foram isolados os esteroides $\beta$-sitosterol, stigmasterol e $\beta$-sitosterona [8]. Outro estudo, usando estrato metanólico, identificou-se uma grande quantidade de mistura de carboidratos, metilmioinositol e derivados de feniletanóides tendo como principal constituinte o cornosídeo [9].

O látex de P. fasciculata é um dos produtos florestais mais importantes comercializado em feiras livres, ervários e farmácias, de cidades como Belém, Igarapé-Miri, Abaetetuba e Barcarena [10, 11]. Segundo Silva et al. (2011) [11] o mercado consumidor do leite de amapá de Belém é abastecido pelos municípios de Ponta de Pedras e Portel, cidades localizadas no arquipélago do Marajó.

$\mathrm{Na}$ medicina popular as formas de usos do látex envolvem diferentes círculos de pessoas, bem como as famílias e as comunidades, envolvidas numa cadeia de trocas de saberes que são passados, oralmente, de geração em geração. Um contexto em que as mulheres atuam ativamente na manutenção da cultura e dos conhecimentos relativos às plantas medicinais [12,13]. O presente estudo objetivou estudar as formas de extração, usos e a comercialização do leite de amapá amargoso na comunidade da ilha Trambioca, Barcarena-PA.

\section{MATERIAL E MÉTODOS}

\section{1. Área de estudo}

O município de Barcarena, pertencente à Mesoregião metropolitana de Belém, no ano de 2018 contava com 122.199 habitantes [14] e área total de 1.316,2 $\mathrm{Km}^{2}$ [15]. A Ilha Trambioca está situada no município de Barcarena, abrangendo uma área de 8.486 hectares, banhada pelos rios Mucuruçá, furo do Arrozal, rio Carnapijó e baía do Marajó [16].

As comunidades distribuídas ao longo da ilha, geralmente, ocupam ambientes ribeirinhos e de terra firme. Duas delas, Arrozal e Carmelo, têm extensões na parte continental, no furo Arrozal e no rio Mucuruça, respectivamente [17]. A principal via de acesso à ilha é feita através da travessia de balsa e pequenas embarcações do rio Mucuruçá, em frente à sede municipal (Figura 1).

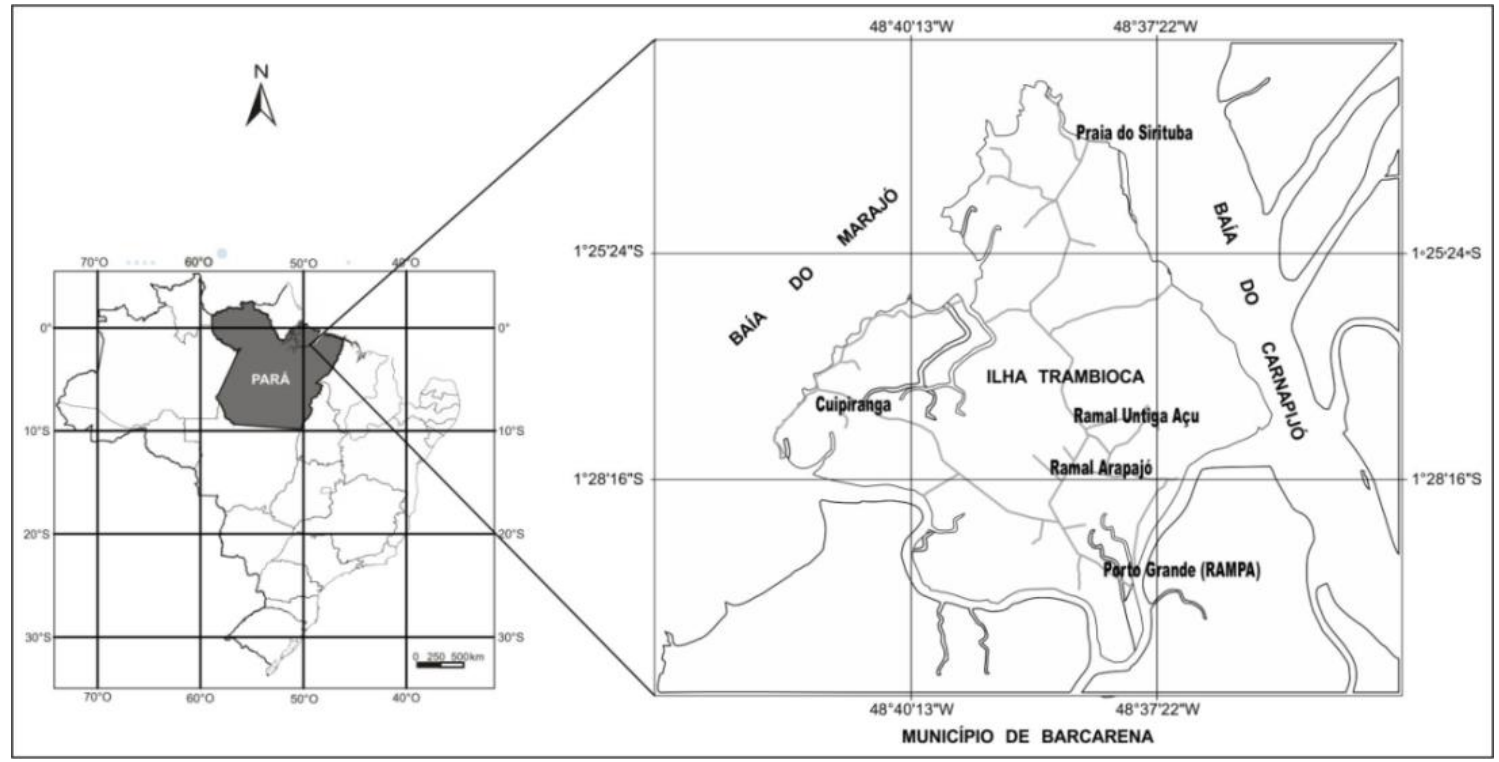

Figura 1. Mapa de localização da ilha Trambioca, município de Barcarena, Pará. 
No interior da ilha Trambioca há a rodovia transtrambioca, da qual se ramificam 25 ramais, garantindo a circulação dos trambioquenses pelas 18 comunidades distribuídas ao longo da ilha. Na extensão litorânea da Trambioca situam-se praias de água doce, sendo as mais frequentadas pelos turistas a do Sirituba e de Cuipiranga [18]. As atividades econômicas mais importantes são a pesca artesanal, agricultura familiar e o extrativismo vegetal.

As localidades Utinga Açu e Arapajó I foram escolhidas para realização da pesquisa, porque nessa região concentrava a maior área de floresta preservada dentro da ilha Trambioca. Além disso, os participantes que tinham conhecimentos sobre as técnicas de extração do leite de amapá, e por isso, denominados de extratores, moravam nessas comunidades.

\subsection{Os entrevistados}

O contato inicial com a comunidade ocorreu através de um líder comunitário, que indicou o primeiro extrator e que recomendou o próximo, repetindo-se o processo a partir de novos incluídos. Considerou-se como consumidor, pessoas que fez uso do leite de leite de amapá pelo menos uma vez, com finalidade medicinal. Dessa forma, os colaboradores foram selecionados por uma abordagem não probabilística "bola de neve" (snowball sampling) [19].

A pesquisa ocorreu nos meses de novembro de 2017 a maio de 2018 e faz parte do projeto "Levantamento etnobotânico de plantas medicinais na ilha Trambioca, Barcarena, Pará, Brasil". O referido projeto foi submetido e aprovado no Comitê de Ética do Instituto de Ciências da Saúde da Universidade Federal do Pará sob parecer 2.481.505 e encontra-se cadastrado no Sistema Nacional de Gestão do Patrimônio Genético e do Conhecimento Tradicional Associado (SisGen), sob o número AD89C0B.

Para coleta dos dados foram aplicados dois questionários semi-estruturados: um para os extratores e o outro para os consumidores de leite de amapá. Informações sobre as formas de extração, quantidade de látex extraído por árvore, os instrumentos utilizados para extração do látex e o tempo em que as árvores levam para recuperação foram levantadas com os extratores. Enquanto que aos consumidores foram abordadas questões relacionadas ao tempo em que residia na ilha Trambioca, renda familiar, grau de escolaridade, as formas de usos e indicações do leite de amapá. Todos os participantes desta pesquisa leram e assinaram um Termo de Consentimento Livre e Esclarecido (TCLE), depois de discutido e aprovado.

\subsection{Coleta e identificação botânica}

A coleta da amostra vegetal e as visitas nas comunidades Utinga Açu e Arapajó I foram por meio de turnê guiada [19]. A coleta e herborização do material botânico seguiram as técnicas descritas por Ming (1996) [20]. A identificação da espécie foi feita por meio de "chaves de identificação" e testos taxonômicos ou por meio dos espécimes coletados com fotos de exsicatas e/ou plantas vivas cujas imagens estavam disponíveis nos sites: Herbário Virtual, JSTOR Plant Science, Flora do Brasil 2020 e TROPICOS. ORG. do Missouri Botanical Garden. Após a identificação, a exsicata foi depositada na coleção biológica do Herbário do Instituto Federal do Pará-Campus Abaetetuba (Voucher 1747).

\subsection{Análise dos dados}

Foi realizada uma análise qualitativa e quantitativa dos dados socioeconômicos e etnobotânicos, tabulados em planilhas do Microsoft Excel 2010 e, posteriormente, organizados visando à compreensão dos mesmos.

\section{RESULTADOS}

\subsection{Os extratores}

Nesse estudo foram incluídos nove extratores de leite de amapá moradores da comunidade ilha Trambioca, sendo três da comunidade Utinga Açu e seis da Arapajó I. O perfil dos extratores e 
os aspectos do sistema de exploração do látex extraído dos amapazeiros estão descritos na tabela 1.

Em relação ao grau de escolaridade, todos os extratores eram alfabetizados, dentre os quais um informou ter concluído o ensino médio e o outro ter graduação. Quanto as ferramentas utilizadas para extração do leite de amapá, os extratores incluídos nessa pesquisa relataram que a machadinha de carpinteiro (instrumento construído artesanalmente pelos extratores) e a faca de seringueiro (instrumento semelhante ao utilizado pelo seringueiros) são as ferramentas mais indicadas para fazer os cortes nas árvores, por causar menos danos na casca. Entretanto, exige mais esforço físico e dependendo da altura, o facão é a melhor ferramenta para fazer as incisões.

Tabela 1. Perfil dos extratores e aspectos do sistema de exploração do látex de amapá na ilha Trambioca, Barcarena, Pará.

\begin{tabular}{|c|c|c|c|c|c|}
\hline Extrativista & Idade & $\begin{array}{l}\text { Ferramenta } \\
\text { usada }\end{array}$ & $\begin{array}{l}\text { Volume } \\
\text { (L)/árvore }\end{array}$ & $\begin{array}{l}\text { Período/horário } \\
\text { para extração }\end{array}$ & Mercado \\
\hline A & 76 & Machado & 0,5 & $\begin{array}{l}\text { Chuvoso/manhã } \\
\text { até as 10:00h. }\end{array}$ & $\begin{array}{l}\text { Consumo } \\
\text { familiar/vizinhos. }\end{array}$ \\
\hline B & 74 & $\begin{array}{l}\text { Faca de } \\
\text { seringueiro }\end{array}$ & 1 a 5 & $\begin{array}{l}\text { Fora do período da } \\
\text { floração/ manhã } \\
\text { até as 10:00h. }\end{array}$ & $\begin{array}{l}\text { Vende sobre } \\
\text { encomenda. }\end{array}$ \\
\hline $\mathrm{C}$ & 39 & Facão & 1 a 2 & Chuvoso/manhã. & $\begin{array}{l}\text { Vende sobre } \\
\text { encomenda }\end{array}$ \\
\hline $\mathrm{D}$ & 50 & Facão & 1 a 6 & $\begin{array}{l}\text { Qualquer período/ } \\
\text { manhã. }\end{array}$ & $\begin{array}{l}\text { Consumo familiar, } \\
\text { vizinhos e venda } \\
\text { sobre encomenda. }\end{array}$ \\
\hline $\mathrm{E}$ & 47 & $\begin{array}{l}\text { Machado e } \\
\text { faca de } \\
\text { seringueiro }\end{array}$ & 1 a 5 & $\begin{array}{l}\text { Fora do período da } \\
\text { floração/ manhã } \\
\text { até as 10:00h. }\end{array}$ & $\begin{array}{l}\text { Vende sobre } \\
\text { encomenda }\end{array}$ \\
\hline $\mathrm{F}$ & 42 & $\begin{array}{l}\text { Facão/ Faca } \\
\text { de } \\
\text { seringueiro }\end{array}$ & 0,5 a 2 & $\begin{array}{l}\text { Qualquer período/ } \\
\text { manhã. }\end{array}$ & $\begin{array}{l}\text { Consumo familiar, } \\
\text { vizinhos e venda } \\
\text { em casa. }\end{array}$ \\
\hline G & 70 & $\begin{array}{l}\text { Facão/ Faca } \\
\text { de } \\
\text { seringueiro }\end{array}$ & 1 a 10 & Chuvoso/manhã & $\begin{array}{l}\text { Vende sobre } \\
\text { encomenda }\end{array}$ \\
\hline $\mathrm{F}$ & 65 & $\begin{array}{l}\text { Facão/ Faca } \\
\text { de } \\
\text { seringueiro }\end{array}$ & 1 a 2 & $\begin{array}{l}\text { Fora do período da } \\
\text { floração/ manhã. }\end{array}$ & $\begin{array}{l}\text { Vende sobre } \\
\text { encomenda }\end{array}$ \\
\hline I & 60 & $\begin{array}{l}\text { Facão/ Faca } \\
\text { de } \\
\text { seringueiro }\end{array}$ & 1 & $\begin{array}{l}\text { Qualquer período/ } \\
\text { manhã. }\end{array}$ & $\begin{array}{l}\text { Consumo familiar } \\
\text { e amigos }\end{array}$ \\
\hline
\end{tabular}

A quantidade de látex retirado por árvore varia entre os extratores residentes na comunidade da ilha Trambioca. Entretanto, eles reconhecem que essas quantidades retiradas dessas árvores estão relacionadas a fatores como a altura, o diâmetro e a forma dos cortes feitos no tronco da árvore. Além desses fatores, cinco dos colaboradores relataram relação entre o tempo em que cada árvore demora para ser explorada novamente e o grau de agressão por ela sofrido.

Os extratores, com apenas duas exceções, relataram que durante os meses de floração e menos chuvoso não é indicado tomar o látex de amapá, pois nesse período ele é tóxico. O melhor período para extrair o produto é pela manhã, no máximo até as 10:00 horas e de preferência em jejum e sem falar com ninguém. 


\subsection{Os consumidores}

Os questionários foram aplicados a 25 pessoas que declararam ter consumido leite de amapá pelo menos uma vez e residiam na ilha Trambioca (11 na comunidade Utinga Açu e 14 na Arapajó I). A média de idade foi de 33 anos, moravam na ilha a pelo menos cinco anos, sendo que dois são maranhenses e um baiano. Entre os 25 colaboradores dessa pesquisa, nenhum declarou não ser alfabetizado e possuir renda familiar menor que um salário mínimo.

Ao responderem a pergunta como obtiveram o conhecimento sobre a utilização do leite de amapá, ficou constatado que a maioria passou a conhecer o látex por meio de sua família, sendo $40 \%$ com a mãe, $20 \%$ com a avó e $16 \%$ com o pai. Além dos familiares $20 \%$ citaram o vizinho e quatro por cento a parteira. Quando questionados por que preferiram tomar leite de amapá aos remédios comprados na farmácia, fatores como a facilidade de conseguir esse produto e por ser natural, permearam todas as respostas.

O leite de amapá amargoso extraído de P. fasciculta apresenta sabor amargo, embora quatro dos consumidores participantes desta pesquisa relataram tomá-lo puro. Entretanto, os demais sugerem uma grande variedade de formas de consumi-lo, misturando com vinho tinto, mel de abelha, café com leite, caribé ou com uma bebida industrializada, comercialmente conhecida como biotônico fontoura.

Em relação às indicações terapêuticas do leite de amapá amargoso, os problemas de saúde tratado foram 20 citações associados ao sistema respiratório (gripe, pneumonia, tuberculose), uma para as verminoses, três para impotência sexual e duas para usar como fortificante.

A cadeia de produção do látex de amapá na ilha Trambioca envolve o extrator, os consumidores local e externo e o atravessador. O consumidor local, em alguns casos, consegue o produto sem custos econômicos. Entretanto, o consumidor externo obtém o leite de amapá através do atravessador que compra do extrator sempre sobre encomenda (Figura 2).

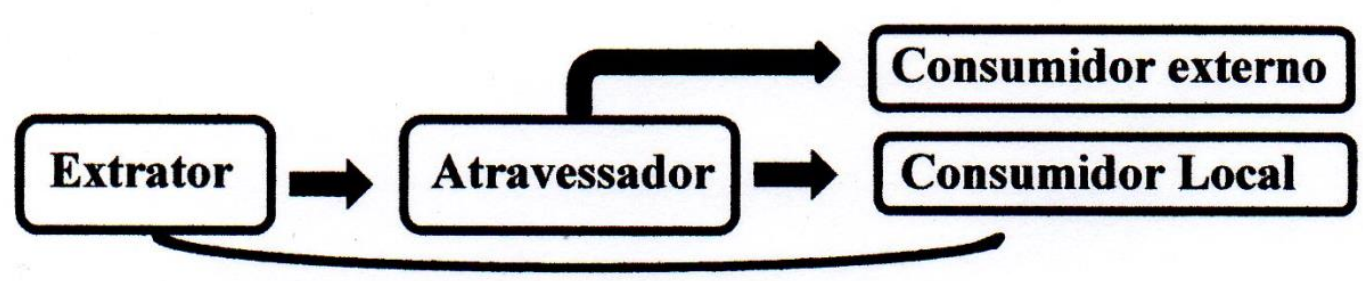

Figura 2. Cadeia produtiva do látex de amapá amargoso na comunidade da ilha Trambioca, Barcarena, Pará.

\section{DISCUSSÃO}

O leite de amapá amargoso é um produto florestal importante na vida dos habitantes da Amazônia, nos anos de 2005, 2007 e 2009 foi comercializado mais de 8.000 litros apenas na região de Belém, capital do Estado [10,11]. A extração desse produto na ilha Trambioca é uma atividade exclusivamente masculina, pois exige muito esforço físico e ainda é preciso percorrer grandes distâncias para selecionar as árvores que serão usadas para retirada do látex. Essas dificuldades contribuem para que seis desses coletores vendam o látex apenas sobre encomenda, mesmo sendo considerado viável economicamente. Além disso, a renda obtida com essa atividade serve apenas para complementação da renda familiar, porque ou já estão aposentados (5 extratores) ou possuem fonte de renda fixa (4 extratores).

Produtos como a casca e óleo de copaíba, leite e casca de sucuuba, sementes de andiroba, casca de mururé e jatobá são também negociados pelos extratores, conforme os relatos de sete, dos nove entrevistados. Esses resultados corroboram com uma pesquisa realizada com 14 extratores do látex de amapá em Pontas de Pedras (PA) que apontam uma correlação significativa entre a renda bruta do extrativismo e número de espécies exploradas [11].

Os extratores incluídos nessa pesquisa demonstraram ter conhecimento dos danos que as diferentes ferramentas utilizadas para extração do leite de amapá podem causar nas árvores de 
amapazeiros. Entretanto, seis (67\%) dos nove, incluídos nessa pesquisa informaram utilizar o facão para extração do látex de amapá. Segundo Serra et al. (2010) [10] no caso do látex de amapá, cada ferramenta tem um impacto significativamente diferente na saúde e no vigor das árvores. As incisões feitas com facões são mais largas e profundas, causando nódulos no câmbio vascular e deformando o painel de extração de látex. Enquanto que os cortes feitos pela faca do seringueiro são estreitos e menos profundos e não alcançam o xilema.

O volume látex obtido por árvores está associado a fatores como a altura e o diâmetro, ao período do ano e ao horário do dia, de retirada do produto. Os colaboradores indicaram os meses de janeiro a julho, como o melhor período para extração do látex de amapá, o que corresponde ao inverno amazônico. Fora dessa época e nos meses de floração o leite de amapá encontra-se tóxico. Em 2005, Plowden e Serra [21], registraram relatos de vendedores e coletores alertando para não colher leite de amapá durante a estação seca.

A idade dos consumidores de leite de amapá incluídos nessa pesquisa está entre 17 e 76 anos, sendo $60 \%$ destes com idade acima de 40 anos e os demais entre 17 e 37 anos, mostrando, portanto que a utilização do leite de amapá amargoso abrangeu todas as faixas etárias dos participantes. Entretanto, entre os extratores $67 \%$ tem mais de 50 anos de idade. Essa discrepância pode ser reflexo da desvalorização, por parte dos mais jovens, de atividades que exige muito esforço físico e pouco reconhecimento social.

Apesar de alguns estudos sugerirem que o elevado preço dos remédios farmacêuticos impulsionam os usos das plantas medicinais [22, 23, 24], entre os moradores da ilha Trambioca as justificativas para o consumo do leite de amapá amargoso foram a facilidade de conseguir o produto $(85 \%)$ e por ser natural $(100 \%)$, causando menos efeitos colaterais.

A duração do tratamento e as doses diárias do leite de amapá, seja puro ou misturado com algum ingrediente, varia muito entre os consumidores. Segundo Sharley et al. (2008) [25] tomar uma colher de sobremesa $(5 \mathrm{~mL})$ em um copo de água $(250 \mathrm{~mL})$ em jejum uma vez ao dia durante 30 dias em casos como bronquite, asma, pneumonia, gastrite, úlcera, inflamações do útero e fortificante, mas no tratamento de tuberculose tomar por 90 dias. Avaliação de toxidade do leite de amapá em humanos faz-se necessária, porém em condições laboratoriais, usando camarões de salmoura (Artemia salina) e ratos Wistar, os resultados sugeriram que o extrato de $P$. fasciculata teve um efeito geral não-tóxico [26].

O uso do leite de amapá amargoso pelos consumidores residentes na ilha Trambioca corrobora com os resultados de outros autores [27, 28, 29] que apontam pessoas usando o látex para combater doenças que acometem o sistema respiratório e fraqueza física. Tais propriedades farmacológicas podem ser atribuídas aos compostos químicos como fenilteranoides, flavonoides e triterpenos encontrados em diversos órgãos da espécie $P$. fasciculata $[9,30]$.

A cadeia produtiva do leite de amapá na ilha Trambioca envolve quatro agentes principais: $o$ extrator, o consumidor local ou extrator e o atravessador. Essa estrutura difere da cadeia produtiva descrita por Serra et al. (2010) [10] devido a presença dos varejistas, vendedores de plantas medicinais no município de Pontas de Pedras, Pará. Os principais destinos do produto são as feiras de Barcarena e do Ver-o-Peso em Belém, sendo a figura do atravessador um elo importante nessa cadeia porque o maior volume de látex exportado da ilha sai sobre encomenda.

As indicações, as formas de preparo e os costumes de uso do látex fazem parte dos conhecimentos e ensinamentos repassados dentro das famílias ou na comunidade da ilha Trambioca. Durante as turnês guiadas percebeu-se que de acordo com algumas tradições locais, $78 \%$ dos extratores ao sair pela manhã de casa não podiam falar com ninguém até começar a extração do exsudado do amapazeiro. O melhor horário para fazer a extração foi pela manhã, no máximo até as 10:00 horas porque o leite engrossa e não escorre ao longo das incisões feitas nas árvores. Além disso, o leite de amapá só deve ser ingerido pela manhã, após ficar exposto ao sereno, antes do sol nascer.

O látex de amapá contribui para o bem-estar da comunidade, a indicações terapêuticas permitem relações sociais de convivência e troca de conhecimento, a medida que as pessoas percebem a necessidade de indicar o remédio caseiro. Essa indicação segue, em geral, um ritual: relatar os casos em que o remédio funcionou; detalhar o modo de preparo; destacar as etapas mais importantes do tratamento que devem ser seguidas e as implicações em não cumpri-las. Nesse contexto, Theisen et al. (2015) [31] destaca que a medicina popular é inicialmente uma medicina 
de saber local, que designa certo modo de transmissão essencialmente oral e gestual, comunicada por intermédio da família e da vizinhança.

\section{CONCLUSÃO}

A cadeia produtiva do látex de amapá é relativamente diversificada na ilha Trambioca, os atores sociais envolvidos são o extrator, o atravessador e os consumidores locais e externos. $\mathrm{O}$ leite de amapá amargoso possui propriedades farmacológicas para o tratamento de doenças que afetam o sistema respiratório e fraqueza física. Os usos do leite de amapá na comunidade permitem relações sociais de convivência e trocas de conhecimentos, contribuindo para o bemestar da comunidade.

\section{AGRADECIMENTOS}

A Universidade Federal do Pará e ao Herbário do Instituto Federal do Pará-Campus Abaetetuba. Aos Colaboradores que aceitaram participar dessa pesquisa.

\section{REFERÊNCIAS BIBLIOGRÁFICAS}

1. Plowden C. Amapá (Parahancornia spp. And Brosimum spp.). In: Shanley P, Pierce AR, Laird SA, Guillen A (eds). Tapping the Green Market: Certification and Management of Non-Timber Forest Products. People and plants conservation series London, UK, Easthscan Publications. xiv; 2002. p. 123-125.

2. Rios M, Martins-da-Silva RCV, Sabogal C, Martins J, Silva RN, Brito RR, Brito IM, Brito MFC, Silva JR, Ribeiro RT. Benefícios das plantas de capoeira para a comunidade Benjamin Constant, Pará, Amazônia Brasileira. Belém: CIFOR, 2001. 54p.

3. Galuppo S, Plowden C. Amapá: o fortificante da Amazônia. In: Shanley P, Medina G (Org.). Frutíferas e plantas úteis na vida amazônica. Belém, CIFOR, 2005. p. 92-96.

4. Matta A. Flora Médica Brasiliense. $3^{\mathrm{a}}$. Edição revista. Manaus: Editora Valer, 2003. 356p.

5. Cavalcante PB. Frutos comestíveis da Amazônia. 6a Ed.- Belém: CNPQ/Museu Paraense Emílio Goeldi. 1996, (Coleção Adolpho Ducke).

6. Silva BC, Duarte JAP, Ferreira GC, Silva AKS, Martins WBR. Morfologia e biometria de frutos e sementes de Parahancornia fasciculata (Poir) Benoist, coletados no Jardim Botânico Rodrigues Alves. V Simpósio de Estudos e Pesquisas em Ciências Ambientais na Amazônia. 2016. p. 89-95.

7. Sobrinho DC, Hauptli MB, Appolinário EV, Kollenz CLM, Carvalho MG, Braz-Filho R. Triterpenoids isolated from Parahancornia amapa. J Braz Chem Soc. 1991;2:15-20.

8. Carvalho MG, Velloso CRX, Braz-Filho R, Costa WF. Acyl-lupeol esters from Paraharnia amapa (Apocynaceae). J Braz Chem Soc. 2001;12:556-559.

9. Carvalho MG, Albuquerque LA, Alves CCF, Cascon V. Cornoside and other constituents from the látex of Parahancornia amapa (Hub.) Ducke (Apocynaceae) a medicinal plant in the Northern Brazil. Rev Bras Farmacol. 2008 dez;18:667-669.

10. Serra M, Shanley P, Melo T, Fantini A, Medina G, Vieira P. From the forest to the consumer: the ecology, local management and trade of amapá amargoso Parahancornia fasciculata (Poir) Benoist in the state of Pará. In: Albuquerque, U.P.; Hanazaki, N. (Eds.). Recent developments and case studies in ethnobotany. Recife: Sociedade Brasileira de Etnobiologia/Núcleo de Publicações em Ecologia e Etnobiologia Aplicada, 2010. p. 213-231.

11.Silva SS, Fantini AC, Shanley P. 2011. Latex de amapá (Parancornia fasciculata (Poir) Benoist, Apocynaceae): remédio e renda na floresta e na cidade. Bol Museu Paraense Emílio Goeldi, Ciências Humanas. 2011 maio-ago; 6(2):287-305.

12.Pires IFB, Sousa AA, Lima CA, Costa JD, Feitosa MHA, Costa SM. Plantas medicinais: cultivo e transmissão de conhecimento em comunidade cadastrada na estratégia Saúde da Família. Rev Bras Pesq Saúde. 2016 out-dez;18(4):37-45. 
13.Santos LSN, Salles MGF, Pinto CM, Pinto ORO, Rodrigues ICS. O saber etnobotânico sobre plantas medicinais na comunidade de Brenha, Redenção, CE. Centro Científico Conhecer. 2018 jul;5(9):409-421. doi: 10.18677/Agrarian_Academy_2018a40.

14.INSTITUTO BRASILEIRO DE GEOGRAFIA E ESTATÍSTICA (IBGE). Território e ambiente. Disponível em: www.ibge.gov.br. Acesso em 10/01/2019.

15.Carmo MBS, Costa SMF. Os paradoxos entre os urbanos no município de Barcarena, Pará. Rev Bras Gestão Urbana. 2016 set/dez;8(3):291-305. doi:10.1590/2175-3369.008.003.A001.

16. Souza APS, Lisboa RCL. Musgos (Bryophyta) na Ilha Trambioca, Barcarena, PA, Brasil. Acta Bot Bras. 2005 dez;19(3):487-492.

17.Simonian LTL. Ilha Trambioca através da história: recursos, ocupações humanas e cultura. In: Simonian, L.T.L (Org.). Gestão em ilha de muitos recursos, história e hábitos: experiências na Trambioca (Barcarena, PA). Belém: NAEA-UFPA; Projeto NAEA/Fundação Ford, 2004. p. 73-136.

18.Lopes AG, Simonian LTL. Gestão dos recursos naturais na ilha Trambioca: Tendências, desafios e possibilidades. In. Lopes, A.G.; Duarte, R.S.; Albuquerque, A.M.; Silva, C.N. Gestão em ilhas de muitos recursos, história e habitantes: experiências na Trambioca (Barcarena, PA) (Org.). Belém: NAEA-UFPA; Projeto NAEA/ Fundação Ford, 2004. p. 381.

19. Albuquerque UP, Lucena RFP, Lins Neto EMF. Seleção dos participantes da pesquisa. In. Albuquerque, U.P.; Lucena, R.F.P.; Cunha, L.V.F.C. (Org.). Métodos e técnicas na pesquisa etnobiológica e etnoecológica. Recife, PE: NUPEEA, 2010. p. 23-37.

20.MING L. C. Coleta de plantas medicinais. In: DI STASI, L. C. (Org.). Plantas Medicinais: Arte e Ciência - Um Guia de Estudo Interdisciplinar. São Paulo: Editora da Universidade Estadual Paulista, 1996.

21.Plowden C, Serra M. Colete com cuidado. In: Shanley P, Medina G (Org.). Frutíferas e plantas úteis na vida amazônica. Belém, CIFOR, 2005. p. 105-106.

22.Cruz VMS, Gonçalves AL, Campos JRP, Reis ARS. Aspectos socioeconômicos e o cultivo de plantas medicinais em quintais agroflorestais urbanos (QAF) no município de Breu Branco, Pará, Brasil. Encic Biofera. 2017 jun; 14(25):158-170. doi: 10.18677/EnciBio_2017A15.

23.Ferreira CD, Brito DRS, Lucena DS, Araújo JM, Sales FCV. Uso medicinal de plantas pela comunidade do bairro Nova Conquista (mutirão) - Patos - PB. Agropecuária Cient Semiárido. 2017 out-dez;12(4):376-382.

24. Wanderley AB, Mousinho KC, Rocha TJM. Plantas medicinais comercializadas por raizeiros em mercados públicos e feira livre de Maceió-AL para tratamento de verminoses. J Med Health Promot. 2017 jul/set;2(3):615-627.

25. Shanley P, Hohn I, Serra M, Habedank H. (Edts.). Receitas sem palavras: plantas medicinais da Amazônia. $2^{a}$ edição. Belém: CIFOR. EMBRAPA, 2008. p. 59.

26. Silva SL, Nascimento AA, Ribeiro EFB, Ribeiro RB, Alves CM, Santos AM, Burmann APR, Mira Neto RA. Avaliação da toxidade de aguda pré-clínica do extrato metanólico das cascas do caule de Parahancornia amapa (Apocynaceae). Acta Amazonica. 2016;46(1):73-80. doi: $10.1590 / 1809-4392201501746$.

27.Amorozo MM, GÉLY A. Uso de plantas medicinais por caboclos do Baixo Amazonas, Barcarena, PA, Brasil. Bol Museu Paraense Emílio Goeldi, Série Botânica, 1998;4(1):47-131.

28. Rêgo LJS, Silva ML, Silva LF, Gama JRV, Reis LP, Reis PC. Caracterização do consumo de cumaru na Amazônia Oriental. Biota Amazônia. 2017 ago;7(4):23-27. doi: 10.18561/21795746/biotaamazonia.

29.Pereira MGS, Coelho-Ferreira M. Uso e diversidade de plantas medicinais em uma comunidade quilombola na Amazônia Oriental, Abaetetuba, Pará. Biota Amazônia. 2017 set; 7(3):57-68. doi:10.18561/2179-5746/biotaamazonia.

30.Santos ACF, Aguiar-Dias ACA, Amarante CB, Coelho-Ferreira M. Estruturas secretoras da lâmina foliar de amapá amargo (Parahancornia amapa, Apocynaceae): histoquímica e doseamento de flavonoides. Acta Amazonica. 2013;43(4):407-414.

31.Theisen GR, Borges GM, Vieira MF. Implantação de uma horta medicinal e condimentar para uso da comunidade escolar. Rev Eletr Gestão Educ Tecnol Amb. 2015 jan-abr; 19 (1): 167 171. doi: $10.5902 / 2236117015546$. 